\title{
HISTOPLASMOSE BUCAL EM PACIENTE HIV - UM RELATO DE CASO
}

Vinicius Villas Boas PETRONI, Joslei Carlos BOHN, Edson Paulo De LEMES, Cassiano Lima CHAIBEN, Antonio Adilson Soares de LIMA

A histoplasmose é uma doença infecciosa que acomete os pulmões com envolvimento dos linfonodos hilares. A etiologia desta doença está associada ao fungo Histoplasma capsulatum. O fungo tem sido isolado de solos com alta concentração de nitrogênio, especialmente aqueles relacionados às fezes de aves e morcegos. No entanto, existe uma forma extrapulmonar da doença que pode envolver quase todos os órgãos. A histoplasmose pode manifestar lesões ulceradas na mucosa orofaríngea ou na região periorofacial. O objetivo deste trabalho é relatar um caso de histoplasmose disseminada com envolvimento do palato mole. Paciente A.W., 39 anos de idade, sexo masculino foi encaminhado ao Hospital Oswaldo Cruz com quadro de fraqueza, emagrecimento, desnutrição e tosse. $O$ paciente teve o diagnóstico de infecção pelo HIV há 5 meses. Ao exame clínico, foram observadas lesões ulceradas em palato mole, na mucosa nasal, na prega aritenóide direita e na pele. $O$ paciente foi submetido à biópsia incisional das lesões do palato e da prega aritenóide. $\mathrm{O}$ exame histopatológico revelou a presença de uma infecção fúngica compatível com Histoplasma capsulatum. O tratamento consistiu na administração de anfotericina por 10 dias, seguido por itraconazol durante 12 semanas. $O$ paciente apresentou uma melhora importante com a remissão das lesões.

Palavras chave: Histoplasmose; Esporos Fúngicos; Palato; Imunossupressão. 